\title{
Short Term Outcomes of Laparoscopic Totally Extraperitoneal Repair of Uncomplicated Groin Hernia Using Polyester Anatomical Mesh Without Fixation
}

\author{
Hamdy Sedky Abdalla*, Sherief Abd-Alfattah Saber, Ahmad Waheed Al-Zayady, \\ Mohammad Hamdy Abo-Ryia, Sherif Abd-Alaziem Mustafa, Gamal Ibrahim Moussa
}

General Surgery Department, Faculty of Medicine, Tanta University, Tanta, Egypt

Email address:

Hamdy.abdallah@med.tanta.edu.eg (H. S. Abdalla)

*Corresponding author

\section{To cite this article:}

Hamdy Sedky Abdalla, Sherief Abd-Alfattah Saber, Ahmad Waheed Al-Zayady, Mohammad Hamdy Abo-Ryia, Sherif Abd-Alaziem Mustafa, Gamal Ibrahim Moussa. Short Term Outcomes of Laparoscopic Totally Extraperitoneal Repair of Uncomplicated Groin Hernia Using Polyester Anatomical Mesh without Fixation. Journal of Surgery. Vol. 5, No. 6, 2017, pp. 86-92. doi: 10.11648/j.js.20170506.11

Received: September 25, 2017; Accepted: September 29, 2017; Published: November 6, 2017

\begin{abstract}
Background: Totally extraperitoneal (TEP) repair of groin hernia can be performed with or without mesh fixation. Fixation can result in postoperative pain or paresthesia due to nerve entrapment. Compared to polypropylene mesh, polyester anatomical mesh (Parietex ${ }^{\circledR}$, Covidien, Mansfield, MA, USA) has a special configuration to fit the posterior inguinal anatomy. Also, the polyester-based chemistry and the rapidly absorbable biological coating increase the hydrophilicity of the mesh, which is thought to result in a fast and intimate tissue ingrowth that may obviate the need for fixation. Patients and Methods: Laparoscopic TEP repair using Parietex ${ }^{\circledR}$ anatomical mesh without fixation was performed for 60 patients presenting with 63 uncomplicated groin hernias. Results: All patients were males with a mean age of $44.7 \pm 14.75$ years. There were $60(95.3 \%)$ primary, $3(5 \%)$ bilateral inguinal and $2(3.3 \%)$ femoral hernias. The mean operative time was $64.8 \pm 22.6$ minutes. There were no major operative complications or conversions to transabdominal preperitoneal or open repair. In the early postoperative period, 54 patients $(90 \%)$ had mild or no pain. Nine patients $(15 \%)$ developed minor postoperative complications. The mean length of hospital stay was $1.1 \pm 0.3$ days and the mean time of return to normal daily activities and to work was $2.6 \pm 0.64$ and $7.15 \pm 1.13$ days respectively. No patient developed chronic groin pain, mesh-related complications or recurrences during the study period. Ninety one percent of patients described their satisfaction with surgery as good or excellent. Conclusion: laparoscopic TEP repair of uncomplicated groin hernia using Parietex ${ }^{\circledR}$ anatomical mesh without fixation is safe and does not increase the risk of hernia recurrence.
\end{abstract}

Keywords: Groin, Hernia, Parietex, Mesh, Laparoscopy, TEP

\section{Introduction}

Inguinal hernia repair is one of the most frequently performed operations in general surgery [1]. Operative techniques have evolved continuously over the past decades establishing tension-free mesh repair as the standard of care [2]. These techniques can be performed via open or laparoscopic surgery [3-4].

Laparoscopic mesh repair of inguinal hernia, compared with conventional hernia repair, provides very promising outcomes. It has all the advantages of preperitoneal repair and minimally invasive surgery with comparable results in terms of recurrence [5-8]. There are two standardized techniques of laparoscopic inguinal hernia repair: transabdominal preperitoneal repair (TAPP) described by Arregui in 1992 and totally extraperitoneal repair (TEP) described by Mc Kernan and Laws in 1993 [9, 10].

TEP is a technically difficult procedure to learn and requires the surgeon to be familiar with the posterior groin anatomy, but, it has the advantage of direct access to posterior defects and non-violation of peritoneal cavity [11]. TEP is performed with or without fixation of the prosthesis. Fixation can result in postoperative pain, neuralgias, or paresthesia due to nerve entrapment or injury to the 
abdominal musculature [12].

Compared to conventional polypropylene (PP) mesh, polyester anatomical mesh $\left(\right.$ Parietex $^{\circledR}$, Covidien, Mansfield, MA, USA) provides larger porosities and an increased softness, while the handleability of the product remains compatible with a laparoscopic placement. Moreover, polyester anatomical mesh has a special configuration to fit the posterior inguinal anatomy. Also, the polyester-based chemistry and the rapidly absorbable biological coating increase the hydrophilicity of the mesh, which is thought to result in a fast and intimate tissue ingrowth that may obviate the need for routine fixation of the mesh [13]. The aim of this study was to assess the short term clinical outcomes of using polyester anatomical mesh $\left(\right.$ Paritex $\left.^{\circledR}\right)$ in TEP repair of uncomplicated groin hernia without fixation and to compare the obtained results to those published in the literature.

\section{Patients and Methods}

\subsection{Study Design}

This study was conducted on 60 patients with 63 groin hernias admitted to Gastrointestinal and Laparoscopic Surgery Unit, General Surgery Department, Tanta University, Egypt during the period from January 2015 to December 2016. The operations were performed by surgeons experienced in laparoscopic surgery. Adult patients with uncomplicated groin hernia were included in the study. Complicated hernia, recurrent hernia after open posterior or laparoscopic repair, complete indirect inguinal hernia (inguinoscrotal) and patients with prior extensive lower abdominal surgery were excluded from the study. Primary end-points were the postoperative pain and hernia recurrence and secondary end-points were the postoperative complications and patients' satisfaction. The study protocol was approved by the "Research Ethics Committee" of the Faculty of Medicine, Tanta University and informed consent was collected from every patient before enrollment in the study.

\subsection{Surgical Technique}

The operating surgeon stands opposite the side of hernia, the camera holder beside him towards the head of the patient and the laparoscopic tower at the patient feet on the side of hernia. The preperitoneal space is accessed through a 10-15 $\mathrm{mm}$ transverse skin incision placed $1 \mathrm{~cm}$ below and lateral to the umbilicus on the side of hernia. The table is positioned in mild Trendelenburg position and slightly tilted towards the surgeon. A $10 \mathrm{~mm} 0^{\circ}$ telescope is inserted and used to open the preperitoneal space until the pubic bone, then replaced by a $30^{\circ}$ one. Two $5 \mathrm{~mm}$ ports are inserted in the midline; one about $1 \mathrm{~cm}$ above the symphysis pubis and the $2^{\text {nd }}$ midway between the other two ports. Dissection starts by opening the retropubic space of Retzius followed by the medial space exposing any direct, femoral or obturator hernia. The lateral space is then dissected till the anterior superior iliac spine by passing between the inferior epigastric vessels and indirect hernia sac. Indirect sac is dissected off the internal ring and cord structure, then, either reduced completely or ligated at its neck and divided distal to the ligature leaving the distal part of the sac in situ. A $15 \times 10 \mathrm{~cm}$ Parietex ${ }^{\circledR}$ anatomical mesh [Figure 1] is introduced through the $10 \mathrm{~mm}$ port and unfolded in the space to cover the entire myopectineal orifice (MPO). No mesh fixation was used. The mesh is maintained in place by 2 graspers and gas released. Ports and telescope are removed and wounds closed.

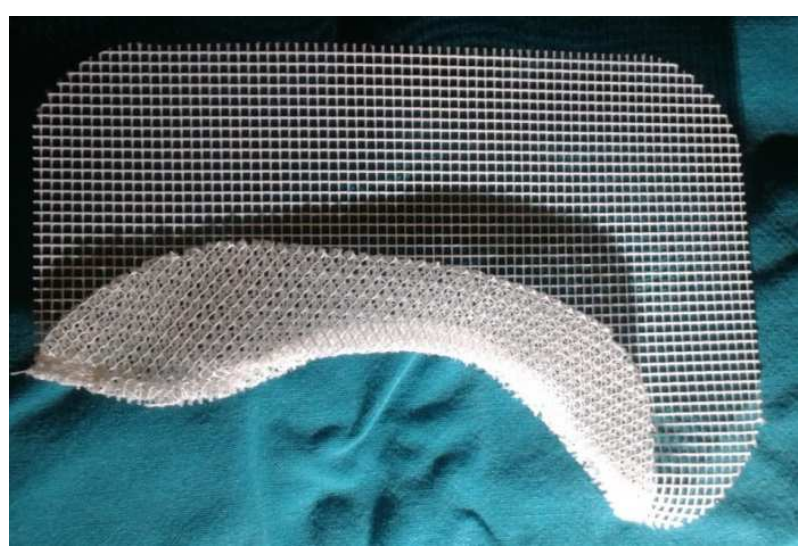

Figure 1. Paritex ${ }^{\circledR}$ Anatomical Mesh (Left Side). Note the 3-D Configuration.

Patients were discharged home when they were independently mobile, self-caring, tolerating oral fluid, comfortable on oral analgesia and with no complications requiring hospital treatment.

\subsection{Follow-up}

Follow-up visits included the initial visit 10 days after surgery, then, regular follow-up visits at 1,3 and 6 months after surgery. During these visits any complications or recurrences were recorded. The time needed to return to normal daily activities and work was recorded. Patients' satisfaction was checked at 3 months after surgery.

\subsection{Data Collection}

Operative data including operative time, complications or conversion were recorded. Postoperative pain severity was assessed using the Numerical Rating Scale (NRS) at 24 h, 10 days and 3 months following the procedure (patients were asked to rate the severest experienced pain whether this was on lying down, standing or ambulating). Post-operative morbidities and duration of hospital stay were recorded.

\subsection{Statistical Analysis}

Data were tabulated and analyzed using IBM SPSS Statistics software package version 20. Metric data were presented as mean and standard deviation, ordinal data were presented as range and median while nominal data were expressed as percentage. $\mathrm{X}^{2}$ test was used to compare ordinal data. A $P$ value of less than 0.05 was considered statistically significant. 


\section{Results}

\subsection{Pre-operative Findings}

All patients were males. The age ranged between 21 and 74 years with a mean of $44.7 \pm 14.75$. The BMI ranged between 22.5 and 43 with a mean of $31.6 \mathrm{Kgm} / \mathrm{m}^{2}$. Forty five hernias $(\mathrm{n}=45 / 63 ; 71.4 \%)$ were bubonocele, $9(14.3 \%)$ were funicular, $7(11.1 \%)$ direct and $2(3.3 \%)$ femoral hernias. Sixty hernias $(n=60 / 63 ; 95.3 \%)$ were primary while the remaining $3(4.7 \%)$ were recurrent after previous anterior repairs. Table 1

Table 1. Patients' Characteristics.

\begin{tabular}{lll}
\hline Variable & No of patients/hernias $(\mathbf{6 0} / \mathbf{6 3})$ & $\%$ \\
\hline Gender & 60 & 100 \\
Male & 0 & 0 \\
Female & & \\
Age $($ years $)$ & $21-74$ & \\
Range & $44.7 \pm 14.75$ & \\
Mean \pm SD & & \\
Body mass Index $\left(\mathrm{Kgm} / \mathrm{m}^{2}\right)$ & $22.5-43$ & \\
Range & 31.6 & 57.14 \\
Mean & & 33.3 \\
Side of hernia & $36 / 63$ & 4.76 \\
Right & $21 / 63$ & \\
Left & $3 / 63$ & \\
Bilateral & & 71.4 \\
Type of hernia & & 14.3 \\
Indirect inguinal & $45 / 63$ & 11.1 \\
a. Bubonocele & $9 / 63$ & 3.3 \\
b. Funicular & $7 / 63$ & 95.3 \\
Direct inguinal & $2 / 63$ & 4.7 \\
Femoral & & \\
Type of hernia & $60 / 63$ & \\
Primary & $3 / 63$ & \\
Recurrent & & \\
\hline & & \\
\hline
\end{tabular}

\subsection{Operative Findings}

The operative time varied between 32 and 110 minutes with a mean of $64.8 \pm 12.6$. Most patients with unilateral hernias $(n=51 / 60 ; 85 \%)$ were operated up on within 90 minutes. There were no conversions to TAPP or open repair and there were no major operative complications. Bleeding from a small tributary of inferior epigastric vein occurred in 1 patient $(\mathrm{n}=1 / 60 ; 1.6 \%)$ and was controlled by compression. In another patient $(1.6 \%)$ there was oozing that required insertion of a vacuum drain for 18 hours. Table 2

Table 2. Operative Findings and Intraoperative Complications.

\begin{tabular}{lll}
\hline Variable & No of patients/hernias $(\mathbf{6 0 / 6 3 )}$ & \% \\
\hline Control of the sac & & \\
Complete reduction & $54 / 63$ & 85.71 \\
Transection of neck & $9 / 63$ & 14.28 \\
Major complications & 0 & 0 \\
Conversions & 0 & 0 \\
Peritoneal tears & $17 / 63$ & 26.9 \\
Minor Bleeding & $1 / 63$ & 1.6 \\
Hypercapnia & $1 / 60$ & 1.6 \\
Operative time (minutes) & & \\
Range & $32-110$ & \\
Mean \pm SD & $64.8 \pm 12.6$ & \\
\hline
\end{tabular}

\subsection{Post-operative Findings}

During the $1^{\text {st }}$ postoperative day, post-operative pain scores ranged between $0-5 ; 54$ patients $(n=54 / 60 ; 90 \%)$ had mild or no pain (score $0-4)$ and 6 patients $(10 \%)$ had moderate pain (score 5). At the $10^{\text {th }}$ postoperative day, pain score ranged between $0-3$ and 45 patients $(n=45 / 60 ; 75 \%)$ were pain free and only 15 patients (25\%) had mild pain (score $1-3)$. At one month after surgery, only 3 patients $(n=3 / 60 ; 5 \%)$ had mild pain (score 1 ). At the $3^{\text {rd }}$ and $6^{\text {th }}$ month postoperatively, all patients were pain free. No patient experienced severe pain, visceral or neuropathic pain. Figure 2

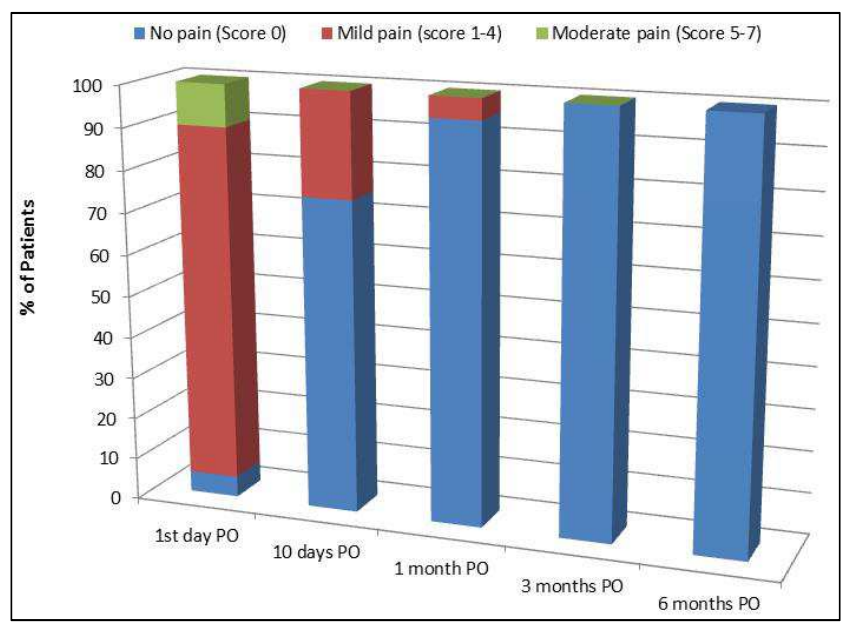

Figure 2. Pain Score of Studied Patients

The mean length of hospital stay was $1.1 \pm 0.31$ days. It was 1 day in 54 patients $(90 \%)$ and 2 days in 6 patients $(10 \%)$.

One patient $(1.6 \%)$ developed surgical emphysema which resolved spontaneously without complications in 12 hours. Small hematomas were observed in 2 patients $(3.2 \%)$ at the umbilical port and small fluid collections at the groin in 6 patients $(10 \%)$ and all resolved spontaneously during the $1^{\text {st }}$ post-operative week. Superficial port sites infection occurred in 2 patients $(10 \%)$ and it responded rapidly to treatment. No testicular complication, mesh-related complications or recurrences were recorded during the follow-up period.

Time needed to return to normal day to day activities varied between 1-4 days with a mean of $2.6 \pm 0.64$ days. Eighty percent of patients resumed normal daily activities within 3 days. Figure 3

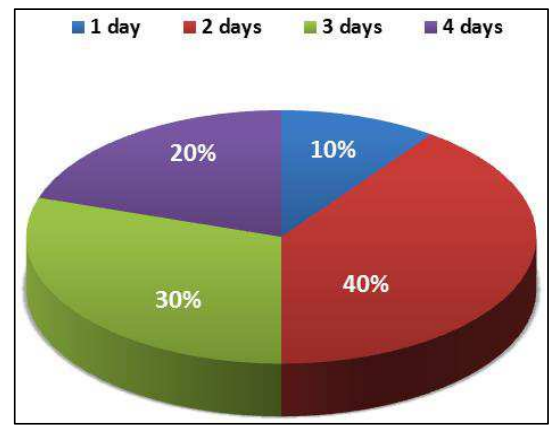

Figure 3. Distribution of Patients According to the Time of Return to Daily Activities. 
Assessment of the time of return to work, however, was difficult because 12 patients $(20 \%)$ had sick leaves and 9 patients $(15 \%)$ were unemployed. In the remaining 39 working patients $(39 / 60 ; 65 \%)$, the time needed to return to work varied between 5-11 days with a mean of $7.15 \pm 1.13$ days. Table 3 At the postoperative day 7, 27 patients (27/39; $69.2 \%$ ) returned to work and at postoperative day 9,36 patients $(36 / 39 ; 92.3 \%)$ were able to return to work.

Table 3. Distribution of Patients According to the Time of Return to Work.

\begin{tabular}{lll}
\hline Time of return to work & No (39 patients) & $\mathbf{\%}$ \\
\hline 5 days & 6 & $15.4 \%$ \\
6 days & 6 & $15.4 \%$ \\
7 days & 15 & $38.4 \%$ \\
8 days & 6 & $15.4 \%$ \\
9 days & 3 & $7.7 \%$ \\
11 days & 3 & $7.7 \%$ \\
\hline
\end{tabular}

Only 54 patients $(90 \%)$ were available for follow-up at $3^{\text {rd }}$ postoperative months and 39 patients $(65 \%)$ at 6 months postoperatively. When asked about the degree of satisfaction of their operations 3 month after surgery, 30 patients $(\mathrm{n}=30 / 54 ; 55.5 \%)$ described it as excellent, 19 patients $(19 / 54 ; 35.2 \%)$ described it as good and 5 patients $(9.2 \%)$ described it as fair. Figure 4

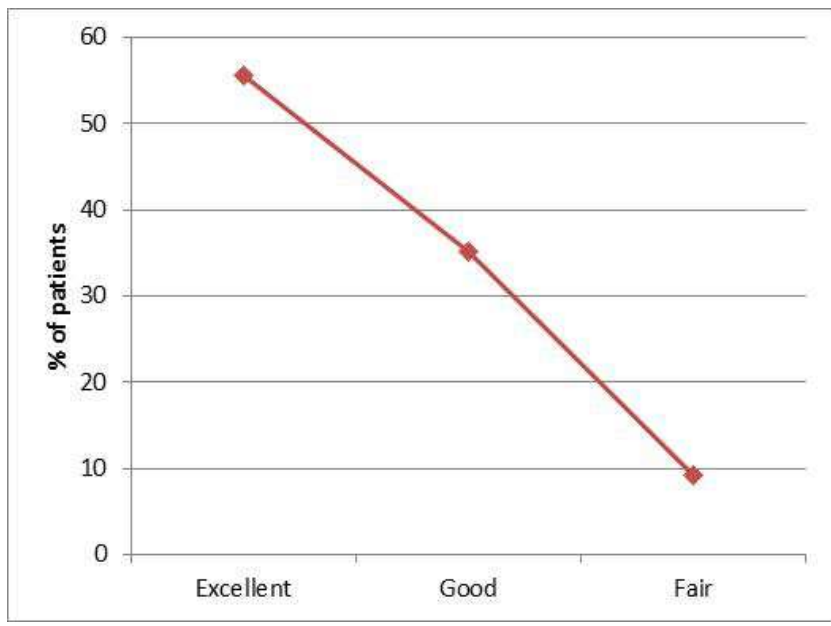

Figure 4. Distribution of Patients According to the Degree of Satisfaction

\section{Discussion}

The introduction of minimal access surgery in the field of groin hernia has established a redefinition of the end points of an acceptable repair including patient's satisfaction, cost and cosmesis, in addition to the classic outcome measures, namely groin pain and recurrence [6].

In spite of markedly reducing recurrence rates, prosthetic materials are often linked to several complications including chronic groin pain and foreign body sensation resulting in reduced quality of life $[14,15]$. It was noted that the choice of the mesh is far more important than the surgical technique as a determinant of the outcome of inguinal hernia repair [16, $17]$.

One potential advantage of polyester is its light weight
[18] which may lead to less long-term scaring and, subsequently, less long-term pain. Another advantage of polyester is its softness without loss of memory making laparoscopic placement easier which may help shorten the learning curve and operative time [19].

The findings in this study showed that using polyester anatomical mesh (Paritex $\left.{ }^{\circledR}\right)$ in laparoscopic TEP repair of uncomplicated groin hernia without fixation is safe, effective and associated with minimal postoperative pain, early return to normal daily and work activities with high patients' satisfaction rate. Also, no mesh-related complications, chronic groin pain or recurrence were recorded during the follow-up period

In this study, a $15 \times 10 \mathrm{~cm}$ polyester anatomical (Parietex $\left.{ }^{\circledR}\right)$ mesh was used with no recorded complications related the type of mesh. On contrary, we touched some of the advantages of this prosthesis. Firstly the 3-D anatomical design of the mesh provided good configuration with the inguinal region making its fixation unnecessary. Secondly, handling of the mesh during laparoscopy was excellent (compared to our previous experience with PP mesh) as it was both soft while maintaining its memory. Finally, no patient suffered from foreign body sensation, stiffness or chronic groin pain which may be attributed to the mesh. These results seem to compare well with those of several other studies [13, 20].

There was no recurrence in this study. This outcome, however, should be interpreted with caution due both to the small sample size and the relatively short follow-up. With the use of mesh, the incidence of hernia recurrence is considerably low [21]. Possible causes of recurrence include using a small sized mesh [22] and displacement of the mesh during desufflation [23]. Strategies to prevent recurrence include using a mesh size 10x15 cm and supporting the medial edge of the mesh during desufflation [23]. Absence of early recurrence in this study suggests that, when these precautions are taken, non-fixation of the mesh does not increase recurrence rate when compared to fixation with regular methods.

Mesh fixation in laparoscopic groin hernia repair is currently a debatable issue. Inadequate mesh fixation has been reported by some authors to be a main cause of hernia recurrence after laparoscopic repair [24, 25]. Although mesh fixation has been linked to an increased incidence of nerve injury and increased post-operative costs, many surgeons think that fixation is necessary to reduce the risk of hernia recurrence [26]. A randomized controlled trial of the early outcome of stapled vs unstapled techniques of laparoscopic TEP repair showed that unstapled repair scores are equivalent to their stapled counterparts with respect to recurrence and complications [27]. Absence of recurrence or chronic pain in this study is comparable to data from recent studies which suggest that mesh fixation in TEP repairs may be avoided without increasing the risk of hernia recurrence and at the same time avoiding neuropathic complications [23, 28, 29]. Besides, mesh non-fixation in an interesting study yielded an unaltered recurrence rate and costs $\$ 500$ less [23]. Fixation 
is, therefore, more expensive than non-fixation [30]. Fortelny reported that fixation and non-fixation of the mesh in TEP repair are associated with equal risk of post-operative pain or recurrence and recommended that non fixation has to be considered in all types of inguinal hernias except large direct defects [31].

Evaluation of postoperative pain in this study showed that most of the patients $(n=54 ; 90 \%)$ had mild or no pain in the $1^{\text {st }}$ postoperative day and at the $3^{\text {rd }}$ postoperative month, all patients were pain-free. No patient in this series experienced severe pain, visceral or neuropathic pain. These results are comparable to those reported in literature $[7,32]$.

No patient developed chronic groin pain in this study. This outcome can be attributed to the type of mesh used and the policy of non-fixation of the mesh. After a mesh based inguinal hernia repair, $11 \%$ of the patients suffer from chronic pain, more than a quarter of these report moderate to severe pain [33]. There is some evidence that the development of chronic pain is influenced by the weight and quality of mesh used. Heavy-weight meshes are less well tolerated by the patients, while, light-weight meshes induce less inflammation and be more favorable in terms of pain reduction [34]. In a meta-analysis by Sajid et al., the authors reported that the incidence of chronic groin pain is significantly reduced after light-weight implantation [35]. Moreover, several studies reported that the risk of acute and chronic pain after stapled mesh fixation is higher compared with fibrin fixation or non-fixation [36, 37]. These studies add more evidence in favors of the anatomical configuration of Parietex ${ }^{\circledR}$ anatomical mesh which doesn't need fixation.

In the present study, the mean operative time in unilateral hernia was $64.8 \pm 22.6$ minutes; a result that didn't differ significantly from that published in literature. There is considerable agreement among laparoscopic surgeons that the learning curve for the laparoscopic TEP is significantly steep [38]. In a systematic review, McCormack et al reported that the mean operative time by surgeons who performed less than 20 TEPs was 95 minutes, while mean operative time by surgeons who performed 30-100 TEPs was 55 minutes [39].

The mean length of hospital stay in the present study was $1.1 \pm 0.31$. Ninety percent of patients stayed one day and $10 \%$ stayed 2 days. These results agree with those of previous studies $[40,41]$. One more study showed also that the length of hospital stay and time needed to resume normal activities were found significantly higher after TEP hernia repair when mesh fixation was used compared to nonfixation [42].

In this study, the mean time needed to return to normal daily activities was $2.6 \pm 0.94$ days and 48 patients $(80 \%)$ resumed normal daily activity during the first three post-operative days. These results are supported by several previous studies including systematic reviews which showed that laparoscopic TEP repair is associated with fast return to normal daily activities. [33, 43]. Besides, a retrospective study on 1,692 laparoscopic TEP without fixation of the mesh showed that non fixation of the mesh is associated with a short hospital stay and early resumption of normal work [28].
The mean duration needed to return to work in this study was $7.15 \pm 1.63$ days. These results are not only comparable to previous studies that confirm early return to work after laparoscopic TEP repair but also are superior to some of them. Kouhia reported the mean return to work after TEP as 14.8 days [41] while, Pawanindra et al. reported it as 12.8 days [44].

About $91 \%$ of patients in this study $(n=49 / 54 ; 90.7 \%)$ described their satisfaction with the operation 3 months after surgery as good or excellent. These results are comparable to several previous studies which showed high patient satisfaction scores following TEP [32, 40, 45].

There were no hernia recurrence in any of the studied patients during the follow up periods; a result that agrees with many similar studies [41, 42].

Indeed this study suffers some limitations. The small sample size, the short duration of follow-up and the absence of a control group are the main limitations of this study.

\section{Conclusion}

Using Parietex ${ }^{\circledR}$ anatomical mesh in laparoscopic TEP repair of uncomplicated groin hernia without fixation is safe with no increased risk of recurrence. The physical properties of this prosthesis facilitate its laparoscopic handling making it a better alternative to conventional PP mesh. A further study on a larger number of patients with a longer follow-up is recommended to evaluate the late outcome of this procedure.

\section{Conflict of Interest Statement}

All the authors do not have any possible conflicts of interest.

\section{References}

[1] Jain SK, Gupta A, Kumar S and Kaza RCM (2014) Laparoscopic vs. open inguinal hernia repair: A systematic review of literature. Asian J Med Sci 5:10-14.

[2] Pahwa HS, Kumar A, Agarwal P, and Agarwal AA (2015) Current trends in laparoscopic groin hernia repair: A review. World J Clin Cases 3 (9): 789-792.

[3] Shouldice E (2003) The Shouldice repair for groin hernias. Surg Clin North Am 83: 1163-1187.

[4] Amato B1, Moja L, Panico S, Persico G, Rispoli C, Rocco N, Moschetti I (2009) Shouldice technique versus other open techniques for inguinal hernia repair. Cochrane Database Syst Rev, DOI: 10.1002/14651858.CD001543.pub4.

[5] Cavazzola L and Rosen M (2013) Laparoscopic versus open inguinal hernia repair. Surg Clin North Am 93: 1269-1279.

[6] Bracale U1, Melillo P, Pignata G, Di Salvo E, Rovani M, Merola G, Pecchia L (2012) Which is the best laparoscopic approach for inguinal hernia repair: TEP or TAPP? A systematic review of the literature with a network metaanalysis. Surg Endosc 26: 3355-3356. 
[7] Basu S, Chandran S, Somers S, Toh SK (2005) Cost effective laparoscopic TEP inguinal hernia repair. Hernia 9: 363-367.

[8] Heikkninen TJ, Haukipuro K, Koivukangas P, Hulkko A (1998) prospective randomized outcome and cost comparison of totally extraperitoneal endoscopic hernioplasty versus Lichtenstein hernia operation among employed patients. Surg Laparosc Endosc 8: 338-44.

[9] Arregui M, Davis C, Yucel O (1992) Laparoscopic mesh repair of inguinal hernia using a preperitoneal approach: a preliminary report. Surg Laparosc Endosc 2:53-58.

[10] McKernan J and Laws H (1993) Laparoscopic repair of inguinal hernias using a totally extraperitoneal prosthetic approach. Surg Endosc 7:26-28.

[11] Misra MC, Bansal VK, Kumar S, Prashant B, Bhattacharjee HK (2008) Total extra-peritoneal repair of groin hernia: prospective evaluation at a tertiary care center. Hernia 12: 6567.

[12] Lau H and Patil NG (2004) Acute pain after endoscopic totally extraperitoneal (TEP) inguinal hernioplasty: Multivariate analysis of predictive factors. Surg Endosc 18: 92-96.

[13] Lepere M, Benchetrit S, Debaert M, B Detruit, Dufilho A, Gaujoux D, J Lagoutte, Martin Saint Leon L, Pavis d'Escurac X, Rico E, Sorrentino J, and Therin J (2000) A multicentric comparison of transabdominal versus totally extraperitoneal laparoscopic hernia repair using Parietex ${ }^{\circledR}$ meshes. JSLS 4: 147-153.

[14] Weyhe D1, Belyaev O, Müller C, Meurer K, Bauer KH, Papapostolou G, Uhl W. (2007) Improving outcomes in hernia repair by the use of light meshes - a comparison of different implant constructions based on a critical appraisal of the literature. Word J Surg 31 (1): 234-244.

[15] Morales-Conde S (2016) Complications after total endoscopic preperitoneal (TEP) repair in: complications in laparoscopic surgery A guide to prevention and management, Edited by Avci C and Schiappa J. Springer, Switzerland (6):81-92.

[16] Eriksen JR, Gögenur I and Rosenberg J (2007) Choice of mesh for laparoscopic ventral hernia repair. Hernia 11 (6): 481-492.

[17] Champault G, Bernard C, Rizk N and Polliand C (2007) Inguinal hernia repair: the choice of prosthesis outweighs that of technique. Hernia 11 (2): 125-128.

[18] Muller M, Klinge U, Conze J, Shumpelick V (1998) Abdominal wall compliance after Marlex mesh implantation for incisional hernia repair. Hernia 20: 113-117.

[19] Abiad F, Voeller G, Wilson R, Mason E. (2003) Polyester (Parietex) mesh for total extraperitoneal laparoscopic inguinal hernia repair Initial experience in the United States. Surg Endosc 17: 498-501.

[20] Cu EG, Katara AN, Domino JP, Wong HB, So JB, Lomanto D, Cheah WK (2010) Comparison between anatomical polyester (Parietex) mesh and polypropylene (Prolene) mesh with fixation in total extraperitoneal repair for inguinal hernia. Asian J Endosc Surg 3 (3): 137-139.

[21] McCormack K, Grant A and Scott N (2003) Laparoscopic techniques versus open techniques for inguinal hernia repair. Cochrane Database Syst Rev, DOI:

\subsection{2/14651858.CD001785.}

[22] Klinge U, Klosterhalfen B, Muller M, Ottinger AP, Schumpelick V (1998) Shrinking of polypropylene mesh in vivo: an experimental study in dogs. Eur J Surg 164 (12): 965969.

[23] Moreno-Egea A, Torralba JA, Morales CG, Aguayo Albasini JL. (2004) Randomized clinical trial of fixation vs nonfixation of mesh in total extraperitoneal inguinal hernioplasty. Arch Surg 139 (12): $1376-1379$.

[24] Lowham AS, Filipi CJ, Fitzgibbons RJ, R Stoppa R, Wantz GE, Felix EL, and Crafton WB (1997) Mechanisms of hernia recurrence after preperitoneal mesh repair. Ann Surg 225: 422-431.

[25] Tetik C, Arregui ME, Dulucq JL, Fitzgibbons RJ, Franklin ME, McKernan JB, Rosin RD, Schultz LS, Toy FK (1994) Complications and recurrences associated with laparoscopic repair of groin hernias: a multi-institutional retrospective analysis. Ann Surg (8): 1316-1323.

[26] Khajanchee Y, Urbach D, Swanstrom L, Hansen PD (2001) Outcomes of laparoscopic herniorrhaphy without fixation of mesh to the abdominal wall. Surg Endosc 15 (10): 1102-1107.

[27] Rajinder P, Kumar R, Hazrah P, Bal S (2005) A randomized comparison of the early outcome of stapled and unstapled techniques of laparoscopic total extraperitoneal inguinal hernia repair. JSLS (9): 403-407.

[28] Garg P, Rajagopal M, Varghese V, Ismail M (2009) Laparoscopic total extraperitoneal inguinal hernia repair with nonfixation of the mesh for 1,692 hernias. Surg Endosc 23: 1241-1245.

[29] Beattie G, Kumar S and Nixon S (2000) Laparoscopic total extraperitoneal hernia repair mesh fixation is unnecessary. $J$ Laparoendosc Adv Surg Tech 10 (2): 71-73.

[30] Chowbey P, Kockerling F and Lomanto D (2011) Technical key points: total extraperitoneal patch plasty (TEP) repair In: Guidelines for laparoscopic (TAPP) and endoscopic (TEP) treatment of inguinal Hernia [International Endohernia Society] (IEHS) Bittner R, Arregui M, Bisgaard T et al Surg Endosc (3):2790-2797.

[31] Fortelny R, Renpold W and Montgomery A (2015) Mesh fixation modalities: is there an association with acute or chronic pain? In: Update guidelines on laparoscopic (TAPP) and endoscopic (TEP) treatment of inguinal hernia (International Endohernia Society), edited by Bittner R, Montgomery M, Bansal V et al. Surg Endosc (9): 303-205.

[32] Roig M, Bertomeu C, Delgado MC, Espinosa RG, Santafé AS, Giner MC (2011) Pain, analgesic consumption and daily activities recovery in patients undergoing ambulatory totally extra-peritoneal laparoscopic inguinal hernioplasty versus ambulatory lichtenstein hernioplasty. Cir Esp 89 (8): 524-531.

[33] Nienhuijs S, Staal E, Strobe L, Rosman C, Groenewoud H, Bleichrodt R (2007) chronic pain after mesh repair of inguinal hernia: a systematic review. Am J Surg 194 (3): 394-400.

[34] Akolekar D, Kumar S, Khan L de Beaux AC, Nixon SJ (2008) Comparison of recurrence with lightweight composite polypropylene mesh and heavyweight mesh in laparoscopic totally extraperitoneal inguinal hernia repair: an audit of 1,232 repairs. Hernia 12: 39-43. 
[35] Sajid MS, Kalra L, Parampalli U, Sains PS, Baig MK (2013) A systematic review and meta-analysis evaluating the effectiveness of lightweight mesh against heavyweight mesh in influencing the incidence of chronic groin pain following laparoscopic inguinal hernia repair. Am J Surg 205 (6): 726736.

[36] Taylor C, Layani L, Liew V, Ghusn M, Crampton N (2008) Laparoscopic inguinal hernia repair without mesh fixation, early results of a large randomized clinical trial. Surg Endosc 22:757-62.

[37] Novik B, Hagedom S, Mork UB, Dahlin K, Skullman S, Dalenbäck J (2006) Fibrin glue for securing the mesh in laparoscopic totally extraperitoneal inguinal hernia repair: a study with a 40-month prospective follow-up period. Surg Endosc 20: 462-467.

[38] Staerkle R, Buchli C, and Villiger P (2009) Patient satisfaction, hernia recurrence rate, and chronic pain 10 years after endoscopic total extraperitoneal inguinal hernia repair. Surg Laparosc Endosc Percutan Tech (19): 405-409.

[39] McCormack K, Wake B, Perez J, Fraser C, Cook J, McIntosh E, Vale L, Grant A (2005) Laparoscopic surgery for inguinal hernia repair: systemic review of effectiveness and economic evaluation. Health Technol Assess (9): 201-203.

[40] Lal P, Kajla RK, Chander J, Saha R, Ramteke VK (2003) Randomized controlled study of laparoscopic total extraperitoneal versus open Lichtenstein inguinal hernia repair. Surg Endosc (17): 850-856.

[41] Kouhia S, Huttunen R, Silvasti S Kouhia ST, Huttunen R, Silvasti SO, Heiskanen JT, Ahtola H, Uotila-Nieminen M, Kiviniemi VV, Hakala T (2009) Lichtenstein hernioplasty versus totally extraperitoneal laparoscopic hernioplasty in treatment of recurrent inguinal hernia: a prospective randomized trial. Ann Surg (249): 384-387.

[42] Koch C, Greenlee S, Larson D et al (2006) Randomized prospective study of totally extraperitoneal inguinal hernia repair: fixation versus no fixation of mesh. JSLS 10: 457-460.

[43] Schmedt C, Sauerland S and Bittner R (2005) Comparison of endoscopic procedures vs Lichtenstein and other open mesh techniques for inguinal hernia repair: a meta-analysis of randomized controlled trials. Surg Endosc 19(2): 188-199.

[44] Pawanindra L., Kajla R., Chander J., et al (2003) Randomized controlled study of laparoscopic total extraperitoneal versus open Lichtenstein inguinal hernia repair. Surg Endosc (17):850-856.

[45] Fujita F, Lahmann B, Otsuka K, Lyass S, Hiatt JR, Phillips EH (2004) Quantification of pain and satisfaction following laparoscopic and open hernia repair. Arch Surg (139):596-602. 